\title{
McDonald's Success Strategy And Global Expansion Through Customer And Brand Loyalty
}

Bahaudin G. Mujtaba, (E-mail: mujtaba@ sbe.nova.edu), Nova Southeastern University Bina Patel, (E-mail: bina@ nova.edu), Nova Southeastern University

\begin{abstract}
The McDonald's Corporation is one of the most successful global restaurant chains around the world. They have used effective management and global expansion strategies to enter new markets and gain a share of the foreign fast food market. This case presents how McDonald's has achieved this enormous success, its best practices in the global food industry, international growth trends and challenges, and various lessons that have been learned from their expansion in foreign countries. Overall, the case provides a discussion of how McDonald's creates both customer and brand loyalty for their products and services. This case focuses on McDonald's international success, challenges and strategies.
\end{abstract}

\section{INTRODUCTION TO THE MCDONALD'S CORPORATION}

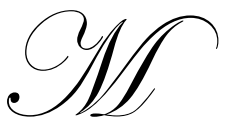

cDonald's leaders believe that people are their most valuable resource as they compete with national and international fast-food giants throughout the world. They invest in their employees' growth and job satisfaction because it is the right thing to do and, perhaps, because their success as a business depends on their commitment to delivering outstanding value. The McDonald's system provides employment and growth opportunities to a vast number of minority groups in the United States and people around the globe. Their commitment to opportunity also includes support for their employee's education. For example, McDonald's Hong Kong offers employees free continuing education courses in business. McDonald's Argentina provides scholarships for employees to study in a degree-granting program that was developed in partnership with a national university. McDonald's UK offers approximately $\$ 1,800$ to each employee to invest in their education, training, or ongoing involvement in sports or the fine arts (VSA Partners, 2004). As can be seen, the McDonald's Corporation invests significant resources in training and retaining employees of diverse backgrounds. Every day, around the world, restaurant crewmembers receive structured on-the-job training and coaching in workplace skills and values. As a matter of fact, diversity initiatives was implemented at McDonald's back in the mid-1970s, under the guidance of former chief executive Fred Turner, who currently is the senior chairman of McDonald's and a member of the board. It all started when Turner's daughters who were working at McDonald's shared some things with him about what was happening on their jobs. That led to the introduction of another initiative around diversity education in the late 1970s known as the "Changing Workforce Seminars." Supported by Turner and upper management, the seminars included education about the changing workforce, followed by career development seminars for women, African-Americans and Hispanics (Smith, 2005).

While the seminars were one of the first diversity directives taken by McDonald's, the employees themselves had started informal networking activities on their own. Many of the employee networks were formed in the mid1970s, including the Women's Leadership Network, Home Office Asian Network, McDonald's Black Employee Network, the Hispanic Steering Committee and others. Those networks eventually evolved into the National McDonald's Diversity Advisory Council, which helped to start the Hispanic Business Vision initiative that focused on ensuring that the brand was more appealing and inviting to Hispanic consumers and employees, whether through bilingual signage, décor', new products or even attitude (Smith, 2005). Socially responsible actions and efforts have given McDonald's a long-standing and distinguished record for diversity-as an employer, franchiser, and purchaser of 
goods and services. They recognize not only a responsibility to provide opportunity, but also the advantages of having diverse backgrounds and perspectives in their system. Approximately 40 percent of McDonald's U.S. owner/operators are minorities and women. In 2004, they purchased more than $\$ 4$ billion in food and paper products from U.S. minority and women suppliers. In their corporate headquarters and U.S. companies in 2004, approximately 26 percent of the managers, not including managers of company-owned restaurants, were minorities and 46 percent were women (VSA Partners, 2004).

McDonald's Corporation, Bank of America, Dell Computers, Disney World, and General Mills are among the Fortune 1000 companies, which have implemented successful strategies to improve the representation of Hispanics at their workforce. Their innovative programs as well as that of ten other companies were included in a best practices study on employment by the Hispanic Association on Corporate Responsibility (HACR) (US Wire, 2002). McDonald's strategic approach to hiring, retaining and promoting Hispanics has resulted in greater representation at all levels of the company. The company supports Hispanic employees through its Hispanic Employee Networks, Hispanic Leadership Council, Hispanic Summits, and Hispanic Steering Committee. All of these groups, in one way or another, support Hispanic employees with career development, and provide the company with valuable information on Hispanic issues.

As a result of McDonald's efforts, today Hispanics represent 29.3 percent of its workforce and 18 percent of its restaurant managers. In addition, two of the three McDonald's USA presidents, and three of six McDonald's global presidents are Hispanic. Ralph Alvarez and Henry Gonzalez are both U.S. Division Presidents, and Eduardo Sanchez is President of Latin America. The company, which is based in Oak Brook, Illinois, also boasts representation in its governance. Enrique Hernandez, Jr., chairman and chief executive officer of Inter-Con Security Systems, is a member of the board of directors. "McDonald's senior leadership's commitment to Hispanic inclusion at all levels of its workforce as well as its governance has provided the company with the competitive edge to continue to excel as the number one restaurant chain in the world," said Anna Escobedo Cabral, president and chief executive officer of HACR.

\section{HUMAN RESOURCE CHALLENGES}

Regardless of location or culture, effective customer brand loyalty can be developed through human resource departments and the company's personnel. The most significant difference between domestic and international human resource management (HRM) seems to be that there far more variables to consider when conducting human resourced audits and training on an international scale, making it more complex than domestic execution. With domestic HRM there is a common standard practice that most companies are familiar with, whereas with international HRM, there are a variety of different laws and business practices that international companies have to consider. Factors such as language translation services, international taxation, international relocation and orientation as well as hostgovernment relations to name a few, are an integral part of successful international HRM. There are steps taken to ensure international employees satisfy their tax requirements for their host country in addition to their home country, which differs according to the each country's specific tax laws. Employers also need to address host-government relations and relocation/orientation issues to ensure that international employees comply with immigration requirements, obtaining work permits as well as housing, expatriate training and medical provisions. The similarities between these two types of HRM can be found on a more practical level of managing employees. Both serve to fulfill the goals, needs of employees, and to ensure that they have the necessary resources to successfully complete their duties. The first step to successful International HRM is an understanding of cultural differences and developing appropriate means of addressing these differences.

The three primary reasons for utilizing international assignments are position filling, management development and organization development. A multinational company may have positions that need to be filled in a timely manner and it is easier for them to simply transfer a current employee who is already skilled in performing the job, as well as familiar with company policies and practices. The other alternative of hiring someone new can be costly as well as time consuming. International assignments also create the opportunity for employees to benefit from management development where the transfer of current staff leads to career development. This can translate into a significant benefit for a company because employees would be skilled in a variety of fields and be more valuable to 
the company as a whole. Another reason for using international assignments is for organization development where companies benefit from cultural diversity. An employee sent on an international assignment in Japan will not only transfer his/her knowledge of their home country's culture, but will also learn a great deal about their host country's culture.

The opening of McDonald's during the early 1990s in Moscow demonstrates the HR demands associated with the new market entry. What did the company do to handle these international challenges? What role did the staff transfers play? One of the fundamental roles that international HRM plays in a new market entry is assisting headquarters in understanding and learning the culture of the new market. This step is essential to make the business successful in all aspects. It is also very important that the local employees understand the company's culture as well. According to Dowling and Welch, "HR activities that build corporate culture include recruitment and selection practices, as firms hire or 'buy' people who appear to hold similar values. Training and development programs, reward systems and promotion are also activities that reinforce company value systems" (2005, p. 48). A business model that works in one country may fail in another if things are not managed in the right way. It has been said that "The many forms of operation modes may demand different skills and place varying stresses on the resources of the company, particularly on its personnel" (Dowling and Welch, 2005, p. 49). Companies take different approaches towards staffing and operating new local markets. In this case, McDonald's "expatriates were involved in assisting with the selection and training of local staff: each crew member received the standard McDonald's training (60 hours of training per crew member). Russians selected for managerial positions were sent to McDonald's Institute of Hamburgerology in Toronto, Canada and to the Hamburger University in Oakbrook, IL, USA" (Dowling and Welch, 2005, p. 50). Among other things, McDonald's had to expatriate individuals that could speak or were willing to learn Russian on one side, and hire people that could speak English, on the other side. Language is a very important aspect of a culture and can easily become an important barrier for business. As explained by Dowling and Welch, "For most large international firms, a common reporting language is necessary for formal and information communication, reporting systems and information flow... Whether deliberately or by default, the language tends to be English. Such language standardization is both a facilitator and a barrier...It does facilitate formal reporting and communication, but only to the extent that people have a required level of fluency in the corporate language." There are many different aspects that a company needs to consider when staffing in a new market, and the role expatriates play in this situations is extremely important since they will not only transfer their knowledge, but also the company's culture.

\section{GLOBAL GROWTH AND SUCCESS STRATEGIES}

Since the start of the company in 1973, McDonald's Corporation began spreading domestically throughout the United States thus establishing its brand recognition. Its initial strategy began by advertising directly to the middle and upper class citizens, as can be seen in countries such as India and China. However, with its many bargain deals on several of its food items, McDonald's began to cater to several people belonging to the lower class.

China was McDonald's first global country in which it researched heavily before opening up restaurants. In fact, through globalization and internationalization, McDonald's was able to develop marketing strategies, while at the same time customizing them for different regions in accordance to the cultural and national variations in order to serve specific target markets. The company conducts heavy research in regions where it desires to open locations based upon a few elements, including social, cultural, technological, political, and economic situations. McDonald's key to success is its business mantra of "think global, act local" (Vignali, 2001). This has allowed the company to achieve financial success in every region it opens its fast food restaurants.

Internationally, McDonald's earns high revenues is India. India is one of the toughest markets to enter for foreign businesses, due to the governmental hardships imposed upon by the Indian government. The reason behind such hardships is solely based on the Indian government seeking to protect its domestic businesses, and employment for its citizens. Vasant Vihar, a prosperous residential area in New Delhi, was the initial location that McDonald's opened up its first store in India in 1996. Since then, almost $60 \mathrm{McDonald}$ 's restaurants have been opened. One of the most successive strategies that McDonald's uses before opening up its stores is research and development of its foods. Tastes and preferences vary across the globe, therefore, the company thoroughly analyzes the preferred tastes, especially to not offend local cultures. For example, India is a nation where beef is highly unpopular due to religious 
purposes; therefore, the company had to come up with burgers that were not made with beef, but rather with chicken or lamb. Furthermore, the company had to create flavors that were spicy in order to meet the general taste preferences. In order to further emphasize the globalization element incorporated by the company, the success strategies include:

\section{Emphasis on Local Management}

Throughout the world, McDonald's prides itself in hiring locals, specifically management in order to gain acceptance into the country by its citizens. The emphasis is based on the "think global, act local" theme of the company. For instance, the company decided to establish two joint ventures with two local entrepreneurs in New Delhi, who were selected to manage the fast food restaurant. This strategic move allowed the company to gain easy access to the bureaucracy associated with the country's government.

\section{Politically Sensitive Strategy}

One of the company's major concerns was to develop ways to avoid political confrontation with the Indian government. The other major concern was to be careful of the religious sensitives in India. Almost $80 \%$ of Indians do not eat beef, and over 150 million Indian Muslims do not eat pork, therefore, instead of supplying the normal Big Mac, which consists of beef, the company developed the Maharaja Mac that is made of two lamb patties. Other foods were also added to the non-standardized menu including McAloo Tiki Burger, and other common Indian dishes.

\section{Employment Opportunity}

Foreign enterprises are often reluctant to hire locals in their companies, specifically at the managerial positions, however, McDonald's research concluded that in order to survive the brutal Indian government, it would have to hire locals as cashiers, cooks, managers, etc., as well as provide jobs for the country's agricultural workforce. In fact, McDonald's outsources its products to several Indian companies throughout India. This provides evidence to the Indian government that McDonald's is not only customer friendly, but also employee friendly.

\section{Environmental Friendliness}

In order to achieve a positive reputation, as well as follow local and national policies of a country, McDonald's tries to establish services that are environmentally friendly. India is an example where the company provides financial contributions and sponsors several community related activities in order to promote environmental protection. This is primarily seen within schools; thus indicating that the company also supports local schools.

\section{Corporate Citizenship}

In order to better its reputation, this multinational firm gives back to the local citizens in all countries it operates. For example, the company provides several financial donations to local organizations. This is one way to encourage consumers to eat at its restaurants, as it is an incentive that is used to spread the name.

\section{Pricing}

As the value of currencies varies worldwide, McDonald's is often forced to change its pricing strategy in accordance to its target market. For instance, the value of a Big Mac varies worldwide (see Chart 1). In Switzerland, the Big Mac is valued \$.60 over the U.S. (price base of the product). However, in China, it is undervalued by $\$ 0.60$ in comparison to the price of the Big Mac in the U.S. It seems that the company tries to maintain a price range on all its products based on the location, income distribution and it is for this purpose that the company opens up most of its restaurants in major cities such as New Delhi, Shanghai, Beijing, and so on. Its primary goal is to initially attract middle and upper class citizens, as they can afford McDonald's prices. After this, they slowly target the lower middle class citizens. In the United States, for example, the restaurant chain has appealed equally well to all classes ranging from the poor to the upper class; however, its popularity continues to be among the lower, middle and upper middle class. 
Chart 1: The Big Mac Index (Source: Economist.com, n.d.)

\section{Big Mac index}

Local currency under $(-3)$ over $(+)$ valuation against the dollar, $\%$

Switzerland

Denmark

Sweden

Euro area

Britain

United States

New Zealland

Turkey

Canada

Chīie

Brazil

Hungary

Mexico

Czech Republic

South Korea

Australia

Taiman

South Africa

Singapore

Japan

Poland

Egypt:

Russia

Phiilippines

Argentima

Hong Kong

Indonesia

Thailand

ria Laysia

Chrīna

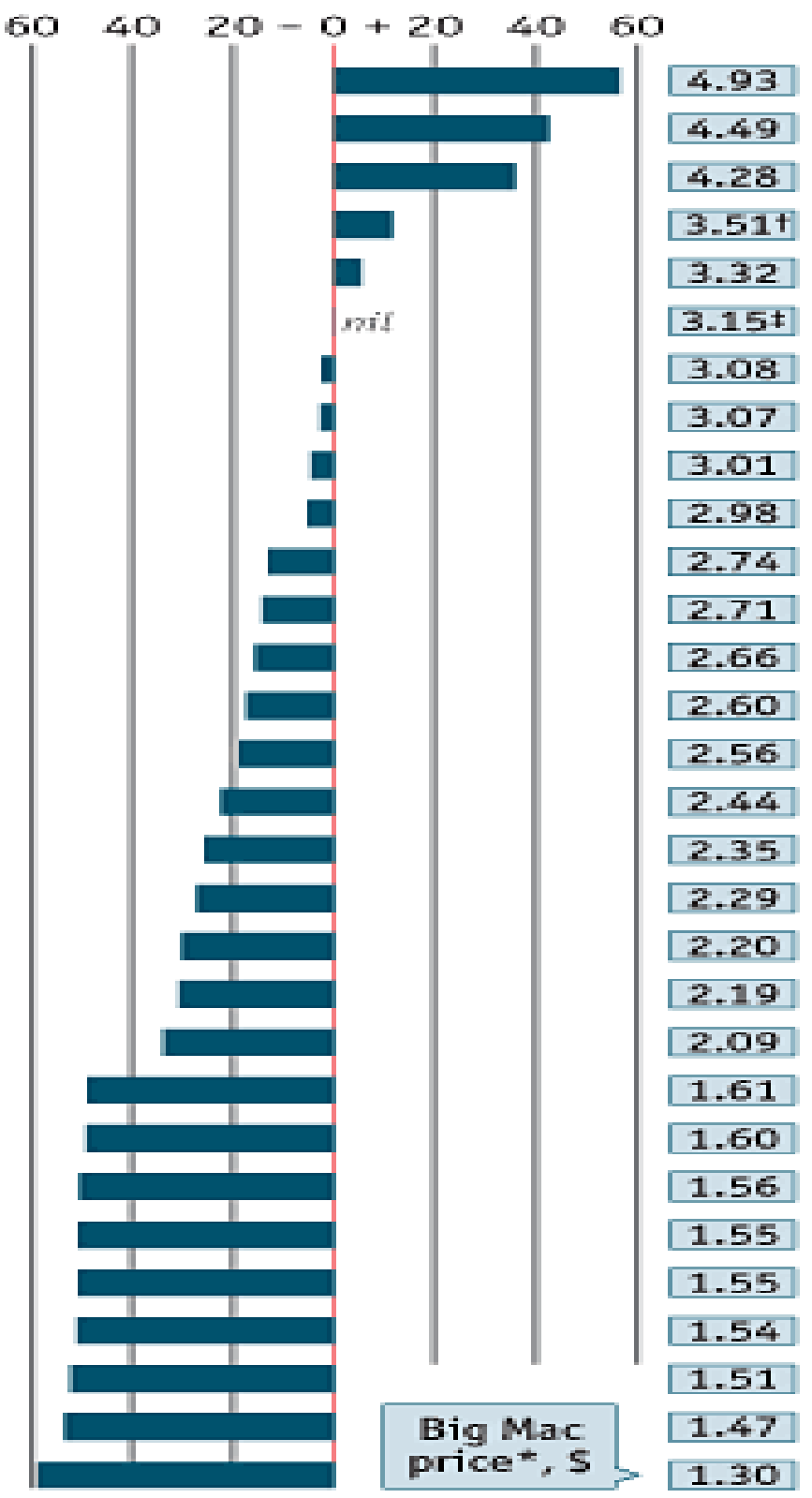

- At market exchange rate l]anuary gthy tWeighted arerage of member countries \#Average af four cities

Source: The Economist using McDonald's price data 


\section{CHALLENGES THE MCDONALD'S HAS OVERCOME}

The company has grown through several challenges that have come its way, including adapting to its local environments; this is an on going challenge that it will face as it continues to open up more restaurants worldwide. However, the biggest challenge the firm faced was in 2001, when the company had hit a low point, specifically with the new fad of eating healthy. This was primarily seen in its home country, the United States. This fad continues today, and as a result, McDonald's became one of the least visited fast food restaurants. In fact, Subway increased in sales due to its low calorie subs that were available. After 2001, the company changed its strategy: instead of opening more stores, the firm decided to change its menu by introducing healthier meals (see chart $2 \mathrm{a}$ ). In fact, the company took a big dip in profits from 2000-2002. However, since its introduction of the new menu, consisting of fruit snacks for children, and healthier meals for adults, such as the grilled chicken flatbread, the company has begun to increase its revenues from the previous slow years. This can be seen in Chart $2 b$, as revenues have begun to increase since 2003. Furthermore, in order to fulfill federal health regulations, as well as meet its healthy requirements to societies in which it operates, the company in 2004, begun to experiment with products. It introduced new oven baked sandwiches, which were healthier and tastier for its consumers. In 2004, as a result of overcoming its challenges, the company increased its shares by $11 \%$ to $12 \%$. McDonald's in Australia, for example, introduced the McCafe, its gourmet coffee for its customers. This proved to be a big hit (Economist.com, 2004).

Chart 2a: Sales Growth (Economist.com, 2004)

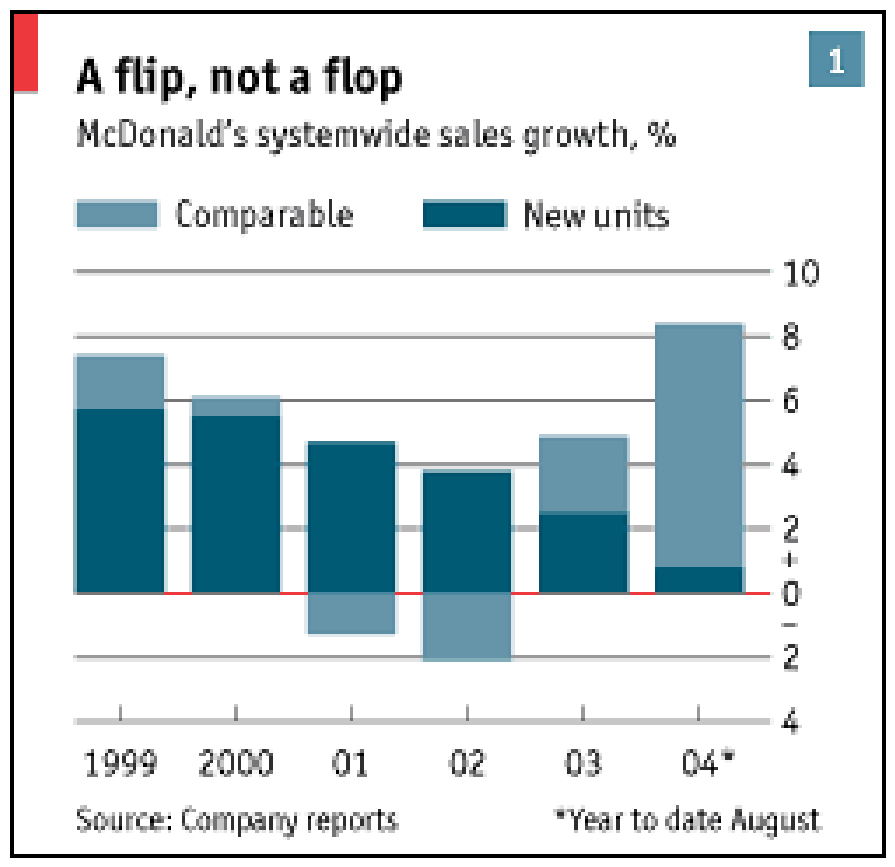


Chart 2b: Total Revenue (Economist.com, 2004)

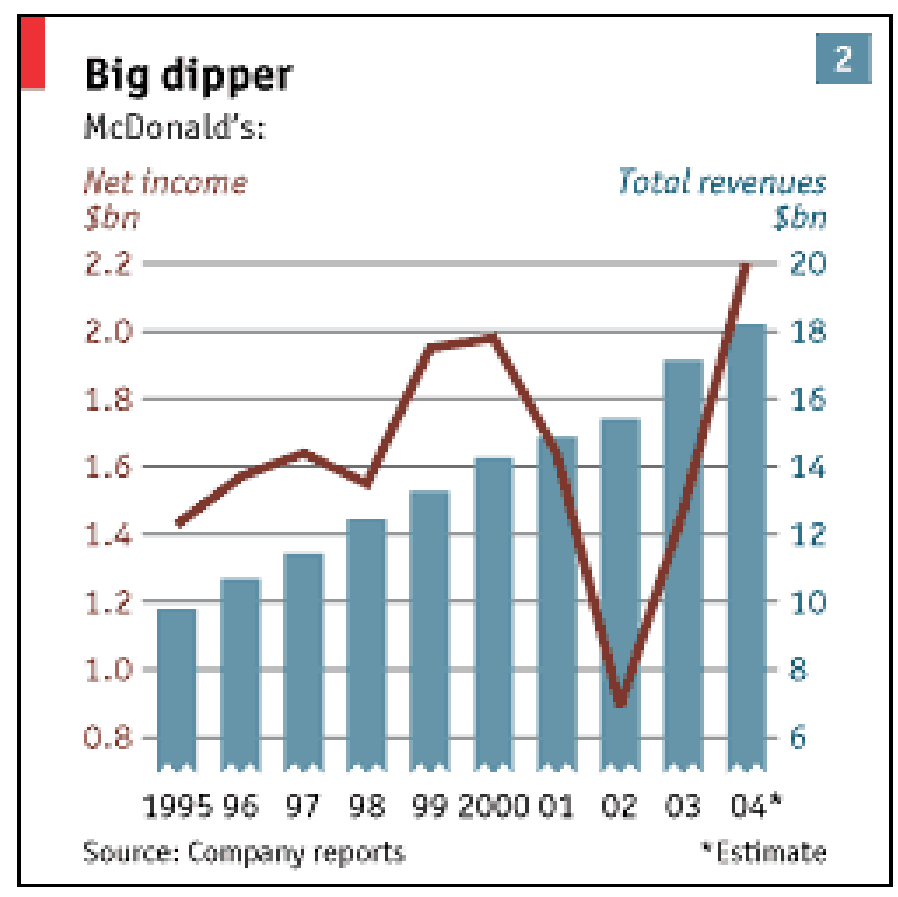

Another way the company begun to increase profits was to introduce its dollar menu. This became popular very quickly, as it allowed even the lower class citizens to eat at McDonald's, not just in the United States, but in countries such as India and China. With its new campaign, larger sizes or portions were introduced at a dollar value, including sodas, fries, salads, and desserts (Eisenberg, 2002). It seems that during the initial years, when the company first began to spread domestically, there were little worries on healthy eating, however, as times have changed and competition has increased, the company has been forced to seek new and innovative ways to not only increase its shares and revenues, but to also fulfill its obligation to the societies in which it operates in.

\section{MCDONALD'S ADOPTING TO NEW MARKETS}

The McDonald Corporation has been able to cater to the needs of their customers in various markets by adjusting their projects, ads and work processes.

As the multi-billion dollar company continues with its spread into the international waters, it has to first research, and then develop its products. Its most recent locations have been India and China. As noted earlier, the company thoroughly conducted in-depth analysis among several states in India in order to meet the preference requirements. For instance, in the state of Gujarat, most citizens are vegetarians, therefore, when the company opened up a location there, it introduced veggie burgers, and other traditional Indian dishes, such as samosas, dosa, vada, and so on. This was not the case in New Delhi, where the company introduced several meat burgers, including Maharaja Mac, kabas, etc. (Dash, 2005). Therefore, in an effort to adapt to the local environment, the company created foods that were more in line with the taste buds of the Indians. This can also be seen in countries such as China, Israel, Venezuela, Mexico, and so on. Recently, the company opened up a retail store, McKids, a clothing retail store in China which appeals to children on the basis of toys, casual modern clothing, interactive books and videos. Other stores were also opened in Europe and the United States in 2005 (People's Daily, 2004). Furthermore, China is the country where high sales are normally generated; and in an effort to keep up these sales, the company has decided to create a new feel for the Chinese people. The Chinese society usually seeks to be more westernized and in an effort to enhance their image and serve the demands of their clients, the company has placed more of an emphasis on beef, which is a luxury item to some customers. The firm has introduced and heavily advertised beef burgers, such as the 
Quarter Pounder. In fact, in order to exhilarate the image of eating beef, it has been advertised that eating beef increases sex appeal; therefore, beef is simply sexy! This is only one of many such ways that the company is promoting its products through its adaptation strategy of becoming local (Towns, 2006). The latest trend in China has been the growth of fast paced restaurants such as McDonald's, which is second in line with the highest number of restaurants in China of over 120, where the majority of these are located in Shanghai. This U.S. based company owns more stores worldwide (about 19,700) than it does in its home country, thus indicating its appeal of internalization. In 2005, the company opened its first drive- thru restaurant in China, with the hope of opening up at least 100 drive-thru outlets by the next two years. In fact, the company expects to increase the number of total restaurants to 1,000 by 2008 (Goldkorn, 2005). The company's adaptation to the local environments in which it operates stores and restaurants have allowed it to achieve success, as well as maintain it.

In fact, McDonald's success has been largely due to its envelopment of globalization, specifically through its adaptation of the local tastes and preferences. Food, specifically fast-food seems to be a weakness among the human race, especially, when it is cheap, convenient and tasty. Yet, this has also led to the company's downfall in its home country during the healthy fad and the growing concerns of obesity among children and adults that the U.S. is going through. However, the company changed its menu in order to accommodate the much desired healthy lifestyle, as well as fulfilling its obligations to provide healthier meals for children. The healthy menu thus carried on over to its global restaurants, where it was tweaked to meet the tastes of the local people. The research and development conducted by the team experts of McDonald's has allowed for a high growth in the company. In the most recent 2006 report (see Chart 3), the company announced that it had grown significantly from the previous year. In the United States, the multinational firm grew by $4.7 \%$ and $4.9 \%$ in Europe. Its largest growth was in the Asian/Pacific region, the Middle East and Africa with 5.7\% (McDonald's.com, 2006). This growth illustrates McDonald's successive strategies of not only adapting to the local environments in which it operates, but also fulfilling society's obligations for healthy lifestyle, donating large funds to various countries and the environment.

Chart 3: McDonald's 2006 Sales Report (Source: McDonald's.com, 2006)

\begin{tabular}{|c|c|c|c|c|}
\hline \multirow{3}{*}{$\begin{array}{l}\text { Percent Inc } \\
\text { Month ended August } 31 \text {, }\end{array}$} & \multirow{2}{*}{\multicolumn{2}{|c|}{$\begin{array}{l}\text { Comparable } \\
\text { Sales }\end{array}$}} & \multicolumn{2}{|c|}{ Systemwide Sales } \\
\hline & & & \multirow{2}{*}{ As } & \multirow{2}{*}{$\begin{array}{l}\text { Constant } \\
\text { Currency }\end{array}$} \\
\hline & 2006 & 2005 & & \\
\hline McDonald's Restaurants* & 6.0 & 3.4 & 8.6 & 7.1 \\
\hline \multicolumn{5}{|l|}{ Major Segments: } \\
\hline U.S. & 3.5 & 3.2 & 4.1 & 4.1 \\
\hline Europe & 8.8 & 3.6 & 14.9 & 10.1 \\
\hline APMEA** & 6.1 & 4.0 & 6.4 & 8.4 \\
\hline
\end{tabular}

Year-To-Date August 31,
McDonald's Restaurants*
$\begin{aligned} & \text { Major Segments: } \\ & \text { U.S. }\end{aligned}$
Europe
APMEA**




\section{RETAINING LOYAL CUSTOMERS}

Experts suggest that if you want loyal customers, then don't stop at customer satisfaction as it takes much more than simply having a few satisfied customers to operate a successful business. The McDonald brand has differentiated itself from competitors not just through customer loyalty, but also through quality, consistency, and standardization to name but a few variables. Author Todd Beck, his article entitled Want loyal customers? Don't Stop at Satisfaction, ${ }^{1}$ states that "Basic service delivery is not enough to differentiate an organization in today's competitive marketplace" (Beck, 2005). Beck states that managers need to understand which service qualities customers' value, and then lead employees toward incorporating these qualities into their daily interactions. The creation of a culture that emphasizes and delivers these values can propel an organization beyond customer satisfaction to the type of loyalty that can drive business growth. According to Beck, over the years, business leaders' focus on improving customer service has produced a host of messages, well-worn phrases or value propositions such as "anything for the customer" and "the customer is always right." According to Beck, as customers become increasingly savvy, products more commoditized and choices more abundant, companies are finding that simply meeting customer expectations (i.e., creating customer satisfaction) does not automatically translate into repeat business. Beck writes that "Indeed, among customers who switch to a competitor, up to eighty percent report being satisfied before making the move. It is when customers feel loyal to an organization that they behave in ways that help grow the business." Companies that guess at what the customer values often miss. Even those that hire expert consultants to do much of formal research can find that they missed something major in their analysis.

Beck states that with all of the "lip service" paid to customer loyalty in today's marketplace, one would think that organizations understand the value of a loyal customer base. Why then do so few provide the kind of customer service that generates loyalty? "The challenge lies in human nature and in the ability of service providers to develop the right attitudes and supporting behaviors" (Beck, 2005). In order to "deliver service performance that inspires customer loyalty, organizations must first understand what customers really want from a service transaction. Research has shown that, regardless of industry, product, age, gender or location in the world, consumers want the following four qualities" (Beck, 2005).

\section{Seamlessness}

Service provider must have the ability to manage service factors that are behind the scenes and invisible to the customer, sparing customers the need to deal with multiple organizational layers or complicated procedures.

\section{Trustworthiness}

Customers wish to feel they are in capable hands and that commitments will be kept. They want and expect things to be correct the first time. Should something go amiss, they expect a quick and thorough recovery.

\section{Attentiveness}

"Customers want to be recognized quickly, politely and with respect. Although this may seem a basic tenet of customer service, attentive service--the quality valued most highly by some customers--tends to be the point at which many organizations fall short" (Beck, 2005). We know from experience that if someone tells a story about being ignored by a representative, listeners often respond with their own "horror stories," each worse than the one before.

\section{Resourcefulness}

Providers who take a fast, flexible approach to the service interaction appeal to customers' desires for resourceful service. If needed, customers also expect prompt and creative problem solving in the service recovery.

\footnotetext{
${ }^{1}$ Article summary provided by Marie Johanne Benjamin, Nova Southeastern University.
} 
Once an organization fully understands what customers expect from a service transaction, then "the next step is to ensure employees both understand and commit to service improvement goals" (Beck, 2005). Beck agrees to generate employee acceptance and to ensure that frontline service delivery reflects the qualities customers value most, organizations should consider the following actions (Beck, 2005):

\section{Communicate}

According to Beck, impart a vision of customer service to your employees that includes clear and understandable long-term goals. "Once employees know the direction the organization plans to take, they are more likely to get behind the effort" (Beck, 2005).

\section{Empower}

Encourage employees to exercise the flexibility and judgment that customers' expect. Employees need to be able to answer a customer's questions and to make routine decisions.

\section{Guide}

The key is to hold supervisors and managers responsible for modeling the skills you expect to see in frontline service personnel.

\section{Show value}

The best result is to make sure that "employees who understand the pay-off are more likely to support the organization's service improvement goals." The most critical factor is to "Help employees see how creating a positive customer experience benefits them, their customers and the organization."

\section{Equip}

Provide the resources your staff requires to succeed, including coaching and training.

\section{Evaluate and compensate}

Establish specific and objective evaluation factors to both measure and encourage behaviors that create positive experiences for customers.

\section{Build for the future}

Recruit, hire and develop employees whose values and priorities are in harmony with the organization.

Most businesses, and the people who run them, assume they know what their customers value, when in fact they have never really made finding out a matter of top priority, this leaves organizations vulnerable. Companies that do not determine-and then regularly take the blinders off and re-determine- what their customers' value often miss fundamental changes. To determine how customers experience value requires more than mere objective, quantitative research. It also requires fresh, unfettered thinking- and listening to maintain loyal customers.

Gathering strategic information on your customer, discovering their unique needs, creating loyalty and guaranteed service program and looking for patterns among former customers are all helpful methods of raising customers' loyalty rates. And in the value-added era, when customers are less loyal than ever, retaining customers is putting money in the bank. The true customer loyalty approach can be one of the most powerful tools any form of industry can follow which will help build a lasting customer relationship. According to Beck, to foster a loyal customer base, organizational leaders must understand that simply satisfying customers won't differentiate their company from the rest of the marketplace. Instead, leaders must commit to delivering the type of customer service 
that exceeds expectations and inspires customers to continue doing business with the organization. The McDonald's Corporation has consistently exceeded the expectations of their customers by inspiring them to repeatedly count on the quality and taste of their meals at any McDonald's round the globe.

\section{SUMMARY}

McDonald's is one of most successful companies in the world today. With its rapid embracement of globalization, the firm has been able to expand and retain numerable growth; as well as continuing to explore with its growth potential in the coming years. From the beginning of the company's development in the United States, to its spread in England, Australia and more recently India and China, the firm has been able to provide a variety of hamburgers and other foods to its consumers. From the Big Mac, to the Maharaja, the company's successive strategies, specifically with heavy research and development have allowed it to fulfill the tastes of locals in every country it operates. Its leaders in all of its major departments have established prices worldwide in all types of currencies, making its foods affordable for customers of all classes. The company's challenges of providing healthier foods to its patrons have contributed to its financial success, thus enabling loyal consumers. In certain countries, such as India and China, eating at a McDonald's has become a luxury, primarily among the middle class, who feel a sense of empowerment that they too can afford to eat at quality restaurants. However, as the company continues to settle into its new environments, it will slowly cater to the lower class, as can be seen in the United States. The strategies developed by its experts, thus allows for the company to increase in revenues, quality, and bring about consumer satisfaction.

\section{REFERENCES}

1. Beck, Todd (2005). Want loyal customers? Don't stop at satisfaction. Customer Relationship Management, 23 (8), February, 1-36 ISSN: 0730-6156

2. Dowling, P. J. and Welch, D. (2005). International Human Resource Management: Managing People in the Multinational Context. 4th Ed. ISBN: 0-324-31866-9.

3. Economist.com (2004). Big Mac's Makeover. Retrieved October 5, 2006, from http://www.economist.com/displaystory.cfm?story $\mathrm{id}=3285898$

4. $\quad$ Eisenberg, D. (2002). Can McDonald's Shape Up? Retrieved October 5, 2006, from http://www.licenseenews.com/news/news85.html

5. Goldkorn, J. (2005). McDonald's to open first drive-through restaurant in China. Retrieved October 10, 2006, from http://www.danwei.org/internet/McDonald's to open_first_drivet.php

6. Kishore, D. (2005). McDonald's In India. Retrieved October 3, 2006, from http://www.thunderbird.edu/about_thunderbird/case_series/2005/_05-0015.htm

7. McDonald's.com. (2006). McDonald's Press Release 09/12/06. Retrieved October 10, 2006, from http://www.McDonald's.com/corp/news/fnpr/2006/fpr_091206.html

8. Mujtaba, B. G. (April 2007). Cross cultural management and negotiation practices. ILEAD Academy Publications; Florida, United States. ISBN: 978-0-9774211-2-1. Website: Ileadacademy.com.

9. Mujtaba, B. G. (2007). Mentoring diverse professionals (2 ${ }^{\text {nd }}$ edition). Llumina Press. ISBN: 1-59526-444-2. Available at: http://www.llumina.com/store/mentoringdiverseprofessionals1.htm

10. Mujtaba, B. G. (2006). Cross cultural change management. ISBN: 1-59526-568-6. Llumina Press, Tamarac, Florida. Website: http://www.llumina.com/store/cccm.htm or www.Llumina.com. Toll free phone: (866) 229-9244 or Reg. (954) 726-0902.

11. People's Daily. (2004). McDonald's targets China's kiddie consumers. Retreived October 5, 2006, from http://english.peopledaily.com.cn/200403/25/eng20040325 138472.shtml

12. Towns, S. (2006). McDonald's China Shows the Sexy Side of Beef. Retrieved October 5, 2006, from http://china.seekingalpha.com/article/17300 


\section{DISCUSSION QUESTIONS}

1. What strategies have made McDonald's so successful in foreign markets that have diverse cultures?

2. What can managers of fast food restaurants do to create customer loyalty?

3. Has McDonald's made any mistakes in their expansion of acquiring new markets and customers around the globe? Research, analyze and discuss the results.

4. What can other organizations learn from the best practices of McDonald's? Discuss.

5. What specific management practices, concept or theories have made McDonald's successful? Discuss.

\section{NOTES}

